\title{
ARID1A serves as a receivable biomarker for the resistance to EGFR-TKIs in non-small cell lung cancer
}

\author{
Dantong Sun, Fei Teng, Puyuan Xing ${ }^{*}$ and Junling Li' ${ }^{*}$
}

\begin{abstract}
ARID1A is a key component of the SWI/SNF chromatin remodeling complexes which is important for the maintaining of biological processes of cells. Recent studies had uncovered the potential role of ARIDIA alterations or expression loss in the therapeutic sensitivity of cancers, but the studies in this field requires to be further summarized and discussed. Therefore, we proposed a series of mechanisms related to the resistance to EGFR-TKIs induced by ARID1A alterations or expression loss and the potential therapeutic strategies to overcome the resistance based on published studies. It suggested that ARIDIA alterations or expression loss might be the regulators in PI3K/Akt, JAK/STAT and NF-KB signaling pathways which are strongly associated with the resistance to EGFR-TKIs in NSCLC patients harboring sensitive EGFR mutations. Besides, ARIDIA alterations or expression loss could lead to the resistance to EGFR-TKIs via a variety of processes during the tumorigenesis and development of cancers, including epithelial to mesenchymal transition, angiogenesis and the inhibition of apoptosis. Based on the potential mechanisms related to ARID1A, we summarized that the small molecular inhibitors targeting ARID1A or PI3K/Akt pathway, the anti-angiogenic therapy and immune checkpoint inhibitors could be used for the supplementary treatment for EGFR-TKIs among NSCLC patients harboring the concomitant alterations of sensitive EGFR mutations and ARIDIA.
\end{abstract}

Keywords: Switch/sucrose nonfermenting, ARID1A, EGFR-TKIs, Resistance, NSCLC

\section{Introduction}

Lung cancer ranks first among all malignancies in cancerrelated mortality, and the 5-year overall survival (OS) is lower than $20 \%$ in China, which causes a serious situation for public health (Allemani et al. 2018). Besides the small cell lung cancer (SCLC), non-small-cell lung cancer (NSCLC) consists of approximately $85 \%$ of all lung cancer cases (Hou et al. 2019a) and the novel therapeutics had achieved a better response than before. NSCLC patients are easily detected harboring cancer genome with highly instability, especially for Asians. Targeted

*Correspondence: xingpuyuan@cicams.ac.cn; lijunling@cicams.ac.cn National Cancer Center/National Clinical Research Center for Cancer/ Cancer Hospital, Chinese Academy of Medical Sciences and Peking Union Medical College, Beijing 100021, China therapeutics based on the driver mutations of NSCLC, such as mutations of epidermal growth factor receptor (EGFR) (Santoni-Rugiu et al. 2019) and rearrangement of anaplastic lymphoma kinase (ALK) (Golding et al. 2018), have significantly prolonged the survival of NSCLC patients. Unfortunately, NSCLC patients harboring sensitive EGFR mutations still could develop the resistance to EGFR-tyrosine kinase inhibitors (TKIs) primarily or secondarily, which leads to treatment failure. According to previous studies, varieties of mechanisms have been proven to be associated with the resistance to EGFR-TKIs, such as the pre-existing T790M mutation of EGFR (Inukai et al. 2006; Lee et al. 2014) which causes the primary resistance to first generation of EGFR-TKIs, insulin-like growth factor 1 receptor (IGF1R) mutation (Sharma et al. 2010), MET amplification (Turke et al. 
2010), hepatocyte growth factor (HGF) mutation (Yano et al. 2008) and mutations leading to sustained activated signaling in other pathways, including the PI3K/AKT pathway (Tan et al. 2015), which causes the resistance to both first generation and third generation of EGFRTKIs. Nevertheless, still a proportion of NSCLC patients harboring sensitive EGFR mutations might develop the resistance to EGFR-TKIs via unknown mechanisms. Hence, it is of great significance to explore the potential mechanism related to the resistance to EGFR-TKIs.

Switch/sucrose nonfermenting (SWI/SNF) chromatin remodeling complexes perform essential roles in a series of biological processes, including DNA replication, gene expression and cell differentiation (Wang et al. 2004; Zhang et al. 2014). In addition, molecules of SWI/SNF chromatin remodeling complexes have been found to be dysregulated frequently in various cancer types (Huang et al. 2015). A variety of subunits of the SWI/SNF chromatin remodeling complexes had been identified, including AT-rich interactive domain 1A (ARID1A) (Michel et al. 2018; Mashtalir et al. 2018) and so on. ARID1A is a key component of the SWI/SNF chromatin remodeling complexes (ARID1A is the key subunit of BAF, while BAF is the main assembly of SWI/SNF complexes) that can bind DNA in a non-sequence-specific manner via alternating the tensity of nucleosome and are involved in the processes of DNA repair and stabilization (Wang et al. 2004; Reisman et al. 2009) which are closely related to the cell fate decision (Pagliaroli and Trizzino 2021) and also serve as a multifunctional regulator of subplate-dependent guidance mechanisms essential to cortical circuit wiring (Doyle et al. 2021). Alterations in ARID1A may be diverse and have been observed in a variety of cancer types, including urothelial carcinoma (Dugas et al. 2019), gastric cancer (Kim et al. 2019) and lung cancer (Huang et al. 2015; Naito et al. 2019) and the variants of ARID1A gene could also be detected through liquid biopsy even for cancers of unknown primary (Laprovitera et al. 2021) as well. Previous studies had demonstrated the essential role of ARID1A in carcinogenesis and cancer development. The loss of ARID1A, which usually lead to the resultant loss of intact BAF, would causes the rapid carcinogenesis across tissues (Wang et al. 2020a). Meantime, loss of ARID1A was found to be associated with the poor prognosis of a variety of cancers including hepatocellular carcinoma (HCC) (Yim et al. 2020) and endometrial carcinoma (EC) (Leo et al. 2021). Researchers had also focused on the role of ARID1A in cancer therapeutics. Andrade confirmed that the intact ARID1A is important in maintaining the sensitivity to radiotherapy in breast cancer via suppressing the accumulation of DNA doublestrand breaks (DSBs) caused by radiation (Andrade et al. 2019). However, whether ARID1A plays a role in the resistance to EGFR-TKIs remains unclear and requires to be further elucidated.

In this review, we concluded a series of the published studies that focused on ARID1A in cancers and proposed the underlying mechanisms related to the resistance to EGFR-TKIs induced by ARID1A alterations or expression loss and the potential therapeutic strategies to overcome the resistance. It suggested that ARID1A might be the regulator in PI3K/Akt, JAK/STAT and NF-kB signaling pathways which are strongly associated with the resistance to EGFR-TKIs in NSCLC patients. Besides, ARID1A alterations or expression loss could contribute to the resistance to EGFR-TKIs via a variety of pathological process during tumor development, including epithelial to mesenchymal transition (EMT), angiogenesis of tumor and the inhibition of apoptosis. According to the potential mechanisms related to ARID1A, we summarized that the small molecular inhibitors targeting ARID1A or PI3K/Akt signaling pathway, the anti-angiogenic therapy and immunotherapy could be used as the supplementary treatment for EGFR-TKIs among NSCLC patients harboring the concomitant alterations of sensitive EGFR mutations and ARID1A. The mechanisms related to $A R I D 1 A$ alterations and expression loss in inducing the resistance to EGFR-TKIs are displayed in Fig. 1.

\section{Underlying mechanisms related to the resistance to EGFR-TKIs treatment in NSCLC induced by ARID1A alterations or expression loss}

According to a latest study, Han et al. (2020) elucidated the potential role of ARID1A alterations in NSCLC patients harboring sensitive EGFR mutations. It suggested that ARID1A alterations are associated with the shorter progression free survival (PFS) of icotinib treatment for NSCLC patients $(P=0.001)$ and related to a higher level of phosphorylation of EGFR protein. Although previous research (Hung et al. 2020) discovered that ARID1A alterations or expression loss correlated with the reduction of the frequency of EGFR mutations, few studies had focused on the mechanisms of ARID1A alteration in inducing the insensitivity of EGFR-TKIs treatment. Therefore, we concluded the potential mechanisms as followed aim to clarify the role of ARID1A in EGFR-TKIs resistance and further explore the direction for research in this field.

\section{The activation of compensatory signaling pathways related to the resistance to EGFR-TKIs induced by ARID1A alterations or expression loss 1. PI3K/Akt signaling pathway}

The abnormal continuous activation of PI3K/Akt signaling pathway was believed to be one of most important signaling pathway resulting in the resistance to both first 


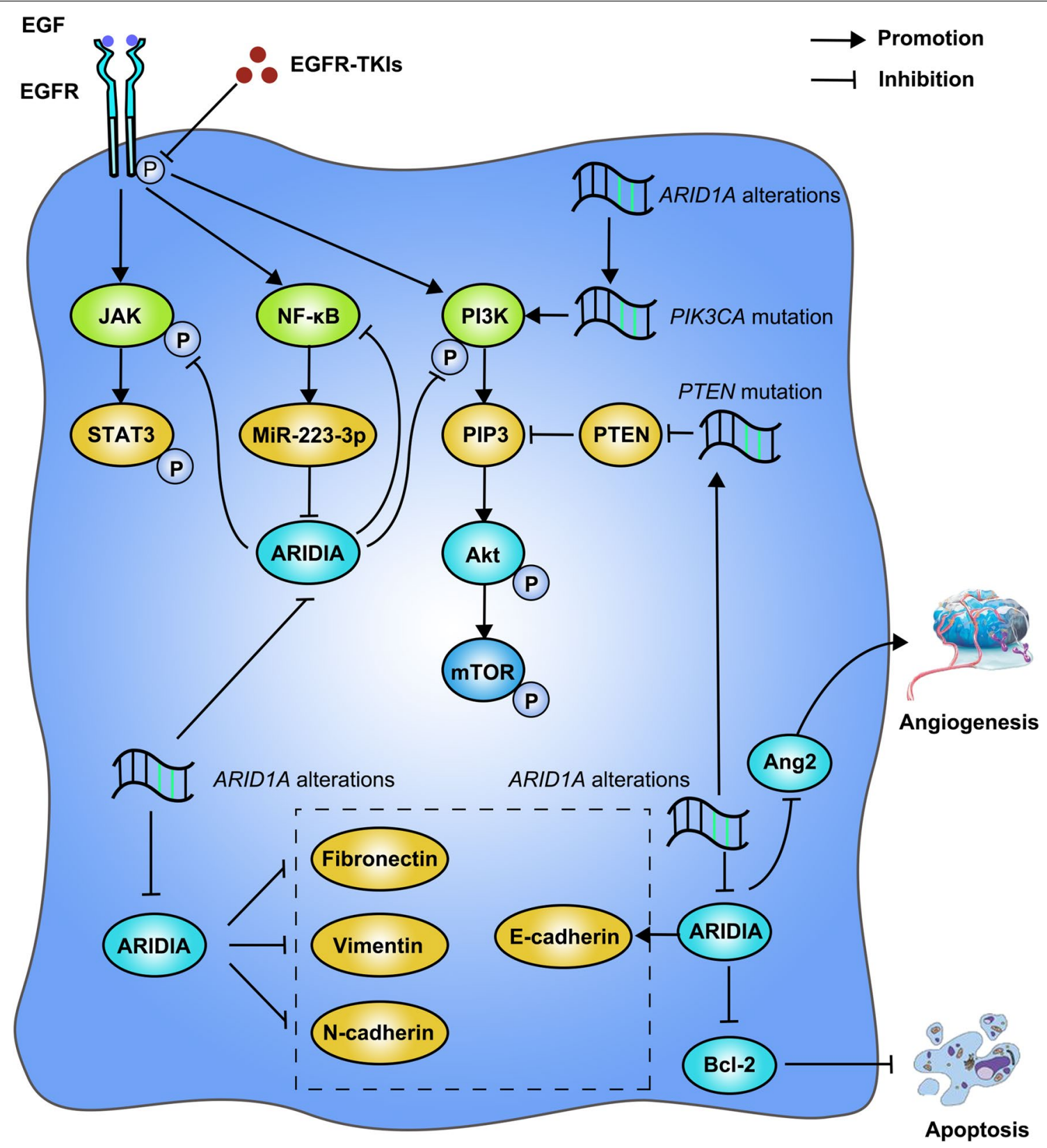

Fig. 1 Mechanisms related to the resistance to EGFR-TKIs induced by ARIDIA alterations or expression loss

generation and third generation of EGFR-TKIs in NSCLC patients (Hrustanovic et al. 2013; Lin et al. 2014). The PI3K/Akt signaling pathway upregulates the phosphorylated level of downstream molecules of EGFR signaling pathway which endows the cancer cell the ability to escape from the inhibition of proliferation induced by EGFR-TKIs and could escape from the apoptosis which results in the development of the disease. In summary of the previous studies, it suggested that ARID1A is strongly believed to be the crucial trigger for the activation of
PI3K/Akt signaling pathway. ARID1A alterations were found to be co-exist with a series of genes related to the PI3K/Akt signaling pathway especially including PTEN and PIK3CA (Samartzis et al. 2013; Takeda et al. 2016; Su et al. 2019). The aberrant of these genes was confirmed to reduce the inhibition of the pathway and result in the continuous activation. As for the expression loss of ARID1A, multiple studies had verified that the loss of ARID1A expression was also related to the alterations of genes belongs to PI3K/Akt signaling pathway (Bosse 
et al. 2013; Huang et al. 2014) and alternate the biological behaviors of tumor cells via this signaling pathway in variety of cancer types (Wiegand et al. 2014; Yang et al. 2019). Especially for the researches for lung cancer, Sun et al. (2021) and Zhang et al. (2014) further clarified the role of ARID1A expression loss respectively in the regulation of NSCLC behaviors via PI3K/Akt/mTOR signaling pathway in vitro and in vivo. It suggested ARID1A expression loss enhances the proliferation, metastasis and inhibits the apoptosis of NSCLC via this signaling pathway which contributed to the poor prognosis of NSCLC patients. To summarize the results above briefly, ARID1A alterations or expression loss could induce the resistance to EGFR-TKIs through the activation of PI3K/ Akt signaling pathway.

\section{JAK/STAT signaling pathway}

JAK/STAT signaling pathway serves as another important downstream pathway of activated EGFR signaling besides PI3K/Akt signaling pathway (Lin et al. 2014) and especially the activation of STAT3 pathway. According to the previous study performed by Alvarez et al. (2006), STAT3 pathway is a critical mediator of the oncogenic effects of somatic EGFR mutations and is necessary for the downstream phosphorylation in NSCLC while the inhibition of STAT3 signaling pathway significantly increased the apoptosis of tumor cells. The relationship between ARID1A alterations or expression loss with the activation of JAK/STAT signaling pathway, especially STAT3 signaling, had also been explored in the published researches. Peng et al. (2020) discovered the function of ARID1A expression loss as the regulator for the related genes of STAT3 signaling pathway and resulted in the impairment of apoptosis via the activated STAT3 signaling. In addition, Fang et al. (2015) proved that the ARID1A expression loss contributes to the tumorigenesis and development of HCC via activating the STAT3 signaling pathway and NF- $\mathrm{kB}$ signaling pathway. In this research, the authors constructed the HCC mouse models with ARID1A knockdown, and it demonstrated the rapid development of the disease compared with the control group. Therefore, we proposed that JAK/STAT signaling pathway plays an important role in the resistance to EGFR-TKIs induced by ARID1A alterations or expression loss. Nevertheless, it requires further clarification for this underlying mechanism.

\section{NF-KB signaling pathway}

$N F-\kappa B$ signaling pathway is considered as the classical pivot signaling pathway related to tumorigenesis and development of malignancies and also confirmed to be associated with the resistance to EGFR-TKIs as described in previous studies (Hrustanovic et al. 2013; Cheong et al. 2018; Feng et al. 2018). As described above, ARID1A expression loss could activate the NF- $\mathrm{KB}$ signaling pathway and significantly change the biological behaviors of HCC (Fang et al. 2015). Besides, Kim et al. ( 2016) suggested that the inhibitors for NF- $k B$ signaling pathway could reverse the resistance to chemotherapeutic drugs and suppress the proliferation conducted by the loss of ARID1A expression in ovarian clear cell carcinoma (OCCC). However, Yang et al. (2018) discovered the different pattern of ARID1A in participating in the NF- $\kappa B$ signaling pathway in their research. It suggested ARID1A serves as the downstream molecule of this pathway, NF- $k B$ firstly stimulates the miR-223-3p expression which could directly bind to ARID1A and then influences the proliferation and migration of tumor cells through the function loss of ARID1A. To summarize the results above, ARID1A expression loss and NF- $\mathrm{KB}$ signaling pathway seem to be the feedback mechanism for the cancers and ARID1A expression loss could develop the resistance to EGFR-TKIs through this feedback mechanism.

\section{The promotion of EMT program induced by ARID1A alterations or expression loss}

EMT program is believed as a crucial pathological process related to the development and metastasis of the malignancies and recent studies had confirmed its critical correlation with the resistance to EGFR-TKIs (Hrustanovic et al. 2013; Lin et al. 2014; Hou et al. 2019b). Besides the acquired metastatic tendency of stromal phenotypic tumor cells after EMT process, group of tumor cells could have the stem-cell like features through EMT process and escape from the inhibition of targeted drugs. The correlation between ARID1A and EMT had been found in previous studies. It suggested that ARID1A alterations are associated with the expression signature of EMT promoters related genes (Wilson et al. 2019). Furthers studies also confirmed the role of ARID1A expression loss in modulating the biomarkers for EMT process through in vitro and in vivo experiments (Wang et al. 2019,2020b; Somsuan et al. 2019; Tomihara et al. 2021). The expression loss of ARID1A upregulates the expression of fibronectin, vimentin and $\mathrm{N}$-cadherin, while downregulates the expression of E-cadherin, which enables the transformation of the tumor cell phenotype to mesenchymal cell type characterized by the loss of cell polarity and the changes of cell morphology. Therefore, we strongly proposed that EMT program could participate into the resistance to EGFR-TKIs induced by $A R I D 1 A$ alterations or expression loss. 


\section{Enhancement of tumor angiogenesis induced by ARID1A alterations or expression loss}

The angiogenesis of tumor serves as another mechanism related to the resistance to EGFR-TKIs which nourishes the tumor cells and enables the cells to invade to the stroma and further metastasis (Alvarez et al. 2006). Recent studies had discovered the important function of ARID1A in regulating the process of angiogenesis. ARID1A expression loss was found tightly associated with the vessel density in solid tumor tissue ( $\mathrm{Hu}$ et al. 2018) and more important, ARID1A expression loss causes the abnormal activation of angiopoietin-2 (Ang2) enhancer and promoter, which eventually leads to the ectopic expression of Ang2 (Hu et al. 2018; Yoodee et al. 2021), which is an essential molecule for angiogenesis process, and the resultant occurrence of the enhancement of angiogenesis. In addition, researchers confirmed that the blockage of Ang2 significantly reduced the density of vessels and the development of HCC with ARID1A deficiency (Hu et al. 2018). Evidences above suggest the underlying mechanism of EMT which is related to the resistance to EGFR-TKIs induced by ARID1A alterations or expression loss.

\section{Inhibition of the apoptosis induced by ARID1A alterations or expression loss.}

It suggested that the expressions of B-cell lymphoma-2 (Bcl-2) family molecules play important roles in balancing the apoptosis and survive of tumor cells and the family was divided into two main group including apoptotic molecules, such as Bax, and anti-apoptotic molecules such as Bcl-2 and Bcl-XL. Specially, the overexpression of Bcl-2 resulting in the inhibition of the apoptosis which lead to the development of the disease and therapeutic resistance including EGFR-TKIs (Hou et al. 2019b). Through the review of the published studies, we discovered the role of $A R I D 1 A$ alterations or expression loss in the regulation of $\mathrm{Bcl}-2$ expression and apoptosis of tumor cells which might participate into the resistance to EGFRTKIs. It elucidated that loss of ARID1A expression could upregulate the expression of $\mathrm{Bcl}-2$ and contribute to the inhibition of apoptosis of tumor cells (Zhang et al. 2018). Besides, researchers suggested that the tumor cells harboring ARID1A alterations showed the therapeutic sensitivity to $\mathrm{Bcl}-2$ inhibitors which indicated the activation of apoptotic pathways induced by ARID1A alterations or expression loss.

\section{Strategies for overcoming the resistance to EGFR-TKIs induced by $A R I D 1 A$ alterations or expression loss 1. Enhancer of zeste homolog 2 (EZH2) inhibitors} $\mathrm{EZH} 2$ is primarily an essential component of polycomb repressive complex 2 (PRC2) which serves a role in epigenetic gene suppression (Yamagishi and Uchimaru 2017). Latest reviews had concluded the role of EZH2 in the poor prognosis of a variety of cancers and the underlying potentiality of EZH2 inhibitors among cancer treatment (Yamagishi and Uchimaru 2017; Kim and Roberts 2016). In this review, we proposed that EZH2 inhibitors could be used in patients harboring ARIDIA alterations or expression loss and serve as a potential option for the supplementary treatment of EGFR-TKIs. Firstly, EZH2 inhibitors is highly selective for the target of ARIDIA alterations or expression loss. Bitler et al. (Bitler et al. 2015) confirmed that EZH2 inhibitors could significantly inhibit the proliferation of OCCC cells with altered ARID1A and either in cells with ARID1A knockdown. It suggested that ARID1A and EZH2 are a pair of important molecules in maintaining the balance of the proliferation and apoptosis of cells while ARID1A serves as the tumor suppressor. ARID1A alterations or expression loss leads to the advantage of EZH2 function and result in the excessive proliferation of tumor cells. Therefore, the purpose of EZH2 inhibition is to draw the balance of ARID1A and EZH2 back to the status before ARID1A alterations or expression loss which might reverse the resistance to EGFR-TKIs induced by ARID1A alterations or expression loss and have the synergistic interaction with EGFR-TKIs.

\section{MTOR inhibitors (rapamycin)}

Previous studies established the role of mTOR inhibitors, especially rapamycin, in the treatment of NSCLC and its' relationship with the administration of EGFR-TKIs. Kwon et al. (2019) proved that the the inhibition of the autophagy via targeting PI3K/Akt/mTOR signaling pathway could overcome the resistance to anti-EGFR treatment in NSCLC. Rolfo et al. (2014) also elucidated that rapamycin could serve as an option for NSCLC patients harboring sensitive EGFR mutations that do not response to EGFR-TKIs. As described above, PI3K/Akt/mTOR signaling pathway serve as the main mechanism related to the resistance to EGFR-TKIs induced by ARID1A alterations and expression loss in NSCLC patients. Therefore, rapamycin might benefit the NSCLC patients harboring the concomitant alterations of EGFR and ARID1A.

\section{Anti-angiogenic therapy}

As far as we concerned, ARID1A alterations or expression loss could upregulate the expression of Ang2 and initiate the process of angiogenesis ( $\mathrm{Hu}$ et al. 2018; Yoodee et al. 2021). In addition, Hu et al. (2018) revealed that the blockage of Ang2 could reverse the change of tumor behaviors induced by ARID1A alterations or expression loss which uncovers the potentiality of anti-angiogenic therapy in overcoming the resistance to EGFR-TKIs, 
such as the treatment of EGFR-TKIs combined with bevacizumab.

\section{Immune checkpoint inhibitors (ICls)}

ICIs had been wildly used in the treatment of cancers recently. According to latest researches, ARID1A was found to be related to the sensitivity of ICIs treatment. $\mathrm{Li}$ et al. (2020) disclosed that the intact ARID1A contributes to the chromatin accessibility and expression to IFN-responsive genes which eventually influence the infiltration of lymphocytes. It suggested that ARID1A has the function of modulating the immune phenotype of cancers. Other studies also pointed that cancer patients harboring ARID1A alterations could benefit from ICIs treatment (Goswami et al. 2020; Takahashi et al. 2021). Although NSCLC patients harboring driver mutations such as $E G F R$ was considered as the group that might not benefit from ICIs, the concomitant alterations of EGFR and ARIDIA might reverse the consequences of the treatment.

\section{Other underlying targets}

Latest studies discovered several novel targets for the treatment of ARID1A-mutated cancers. It suggested that the inhibition of GLS1 (Wu et al. 2021) or CCNE1 (Kawahara et al. 2021) could significantly suppress the proliferation of ARID1A-mutated cancer cells in vitro and in vivo, respectively, but not in the wild type cells. Another study also confirmed that the inhibition of ATM/Chk2 DNA damage checkpoint axis would exhibit anti-cancer efficacy only in ARID1A-mutated cancer cells (Wang et al. 2020c). Targets above would provided us with more options for the treatment of ARID1A-mutated cancer but requires further studies.

\section{Conclusion}

ARID1A is the regulator a series of signaling pathways, including PI3K/Akt, JAK/STAT and NF-KB signaling pathway and related to the resistance to EGFR-TKIs in NSCLC patients. Besides, ARID1A alterations or expression loss could lead to the resistance to EGFR-TKIs via enhancing the EMT, angiogenesis and the inhibition of apoptosis in NSCLC. In order to overcome the resistance to EGFR-TKIs related to ARID1A, EZH2 inhibitor, rapamycin and the anti-angiogenic therapy could be used for the supplementary treatment for NSCLC patients that do not response to EGFR-TKIs.

\footnotetext{
Abbreviations

SCLC: Small cell lung cancer; NSCLC: Non-small-cell lung cancer; EC: Endometrial carcinoma; EGFR: Epidermal growth factor receptor; ALK: Anaplastic lymphoma kinase; IGF1R: Insulin-like growth factor 1 receptor; HGF: Hepatocyte growth factor; SWI/SNF: Switch/sucrose nonfermenting; ARID1A: AT-rich interactive domain 1A; DSBs: DNA double-strand breaks; EMT: Epithelial to
}

mesenchymal transition; PFS: Progression free survival; HCC: Hepatocellular carcinoma; OCCC: Ovarian clear cell carcinoma; Ang2: Angiopoietin-2; BCl-2: B-cell lymphoma-2; EZH2: Enhancer of zeste homolog 2; ICls: Immune checkpoint inhibitors.

\section{Acknowledgements}

We kindly acknowledge the support of Prof. Helei Hou from the Affiliated Hospital of Qingdao University.

\section{Authors' contributions}

Conception/Design: JL and PX; Manuscript writing: DS and FT. All authors read and approved the final manuscript.

\section{Funding}

Not applicable.

Availability of data and materials

Not applicable.

\section{Declarations}

Ethics approval and consent to participate Not applicable.

Consent for publication

All authors approved for the publication.

\section{Competing interests}

The authors declared no conflict of interests.

Received: 24 Auqust 2021 Accepted: 14 October 2021

Published online: 29 October 2021

\section{References}

Allemani C, Matsuda T, Di Carlo V, Harewood R, Matz M, Nikšić M, Bonaventure A, Valkov M, Johnson CJ, Estève J, Ogunbiyi OJ, Azevedo E Silva G, Chen WQ, Eser S, Engholm G, Stiller CA, Monnereau A, Woods RR, Visser O, Lim GH, Aitken J, Weir HK, Coleman MP; CONCORD Working Group. Global surveillance of trends in cancer survival 2000-14 (CONCORD-3): analysis of individual records for 37513025 patients diagnosed with one of 18 cancers from 322 population-based registries in 71 countries. Lancet. 2018, 391 (10125): 1023-1075.

Alvarez JV, Greulich H, Sellers WR, Meyerson M, Frank DA. Signal transducer and activator of transcription 3 is required for the oncogenic effects of non-small-cell lung cancer-associated mutations of the epidermal growth factor receptor. Cancer Res. 2006;66(6):3162-8.

Andrade D, Mehta M, Griffith J, Oh S, Corbin J, Babu A, De S, Chen A, Zhao YD, Husain S, Roy S, Xu L, Aube J, Janknecht R, Gorospe M, Herman T, Ramesh $R$, Munshi A. HuR reduces radiation-induced DNA damage by enhancing expression of ARID1A. Cancers (basel). 2019;11(12):2014.

Bitler BG, Aird KM, Garipov A, Li H, Amatangelo M, Kossenkov AV, Schultz DC, Liu Q, Shih IM, Conejo-Garcia JR, Speicher DW, Zhang R. Synthetic lethality by targeting EZH2 methyltransferase activity in ARID1A-mutated cancers. Nat Med. 2015;21(3):231-8.

Bosse T, ter Haar NT, Seeber LM, v Diest PJ, Hes FJ, Vasen HF, Nout RA, Creutzberg CL, Morreau H, Smit VT. Loss of ARID1A expression and its relationship with PI3K-Akt pathway alterations, TP53 and microsatellite instability in endometrial cancer. Mod Pathol. 2013, 26(11): 1525-1535.

Cheong HT, Xu F, Choy CT, Hui CWC, Mok TSK, Wong CH. Upregulation of BCl2 in NSCLC with acquired resistance to EGFR-TKI. Oncol Lett. 2018;5:901-7.

De Leo A, de Biase D, Lenzi J, Barbero G, Turchetti D, Grillini M, Ravegnini G, Angelini S, Zamagni C, Coluccelli S, Dondi G, De laco P, Perrone AM, Tallini G, Santini D, Ceccarelli C. ARID1A and CTNNB1/ $\beta$-Catenin molecular status affects the clinicopathologic features and prognosis of endometrial carcinoma: implications for an improved surrogate molecular classification. Cancers (basel). 2021;13(5):950. 
Doyle DZ, Lam MM, Qalieh A, Qalieh Y, Sorel A, Funk OH, Kwan KY. Chromatin remodeler Arid la regulates subplate neuron identity and wiring of cortical connectivity. Proc Natl Acad Sci USA. 2021;118(21):e2100686118.

Dugas SG, Müller DC, Le Magnen C, Federer-Gsponer J, Seifert HH, Ruiz C, Savic Prince S, Vlajnic T, Zellweger T, Mertz KD, Bacon JVW, Wyatt AW, Rentsch CA, Bubendorf L. Immunocytochemistry for ARID1A as a potential biomarker in urine cytology of bladder cancer. Cancer Cytopathol. 2019;127:578-85.

Fang JZ, Li C, Liu XY, Hu TT, Fan ZS, Han ZG. Hepatocyte-specific Arid1a deficiency initiates mouse steatohepatitis and hepatocellular carcinoma. PLOS ONE. 2015;10(11):e0143042.

Feng CJ, Xian QJ, Liu ST. Micro RNA-518 inhibits gastric cancer cell growth by inducing apoptosis via targeting MDM2. Biomed Pharmacother. 2018;97:1595-602.

Golding B, Luu A, Jones R, Viloria-Petit AM. The function and therapeutic targeting of anaplastic lymphoma kinase (ALK) in non-small cell lung cancer (NSCLC). Mol Cancer. 2018;17(1):52.

Goswami S, Chen Y, Anandhan S, Szabo PM, Basu S, Blando JM, Liu W, Zhang J, Natarajan SM, Xiong L, Guan B, Yadav SS, Saci A, Allison JP, Galsky MD, Sharma P. ARID1A mutation plus CXCL13 expression act as combinatorial biomarkers to predict responses to immune checkpoint therapy in mUCC. Sci Transl Med. 2020;12(548):eabc4220.

Han X, Luo R, Wang L, Zhang L, Wang T, Zhao Y, Xiao S, Qiao N, Xu C, Ding L, Zhang Z, Shi Y. Potential predictive value of serum targeted metabolites and concurrently mutated genes for EGFR-TKI therapeutic efficacy in lung adenocarcinoma patients with EGFR sensitizing mutations. Am J Cancer Res. 2020;10(12):4266-86.

Hou H, Sun D, Liu K, Jiang M, Liu D, Zhu J, Zhou N, Cong J, Zhang X. The safety and serious adverse events of approved ALK inhibitors in malignancies: a meta-analysis. Cancer Manag Res. 2019a;11:4109-18.

Hou H, Sun D, Zhang X. The role of MDM2 amplification and overexpression in therapeutic resistance of malignant tumors. Cancer Cell Int. 2019;19:216. https://doi.org/10.1186/s12935-019-0937-4.

Hrustanovic G, Lee BJ, Bivona TG. Mechanisms of resistance to EGFR targeted therapies. Cancer Biol Ther. 2013;14(4):304-14.

Hu C, Li W, Tian F, Jiang K, Liu X, Cen J, He Q, Qiu Z, Kienast Y, Wang Z, Zhang H, $\mathrm{Ji} Y, \mathrm{Hu} J$, Hui L. Arid1a regulates response to anti-angiogenic therapy in advanced hepatocellular carcinoma. J Hepatol. 2018;68(3):465-75.

Huang HN, Lin MC, Huang WC, Chiang YC, Kuo KT. Loss of ARID1 A expression and its relationship with PI3K-Akt pathway alterations and ZNF217 amplification in ovarian clear cell carcinoma. Mod Pathol. 2014;27(7):983-90.

Huang HT, Chen SM, Pan LB, Yao J, Ma HT. Loss of function of SWI/SNF chromatin remodeling genes leads to genome instability of human lung cancer. Oncol Rep. 2015;33:283-91.

Hung YP, Redig A, Hornick JL, Sholl LM. ARID1A mutations and expression loss in non-small cell lung carcinomas: clinicopathologic and molecular analysis. Mod Pathol. 2020;33(11):2256-68.

Inukai M, Toyooka S, Ito S, et al. Presence of epidermal growth factor receptor gene T790M mutation as a minor clone in non-small cell lung cancer. Cancer Res. 2006;66:854-8.

Kawahara N, Yamada Y, Kobayashi H. CCNE1 is a putative therapeutic target for ARID1A-mutated ovarian clear cell carcinoma. Int J Mol Sci. 2021;22(11):5869.

Kim KH, Roberts CWM. Targeting EZH2 in cancer. Nat Med. 2016;22:128-34.

Kim M, Lu F, Zhang Y. Loss of HDAC-mediated repression and gain of NF-KB activation underlie cytokine induction in ARID1A- and PIK3CA-mutationdriven ovarian cancer. Cell Rep. 2016;17(1):275-88.

Kim YB, Ahn JM, Bae WJ, Sung CO, Lee D. Functional loss of ARID1A is tightly associated with high PD-L1 expression in gastric cancer. Int J Cancer. 2019;145:916-26.

Kwon Y, Kim M, Jung HS, Kim Y, Jeoung D. Targeting autophagy for overcoming resistance to anti-EGFR treatments. Cancers (Basel). 2019;11(9):1374.

Laprovitera N, Salamon I, Gelsomino F, Porcellini E, Riefolo M, Garonzi M, Tononi P, Valente S, Sabbioni S, Fontana F, Manaresi N, D'Errico A, Pantaleo MA, Ardizzoni A, Ferracin M. Genetic characterization of cancer of unknown primary using liquid biopsy approaches. Front Cell Dev Biol. 2021;9:666156.

Lee Y, Lee GK, Lee YS, et al. Clinical outcome according to the level of preexisting epidermal growth factor receptor T790M mutation in patients with lung cancer harboring sensitive epidermal growth factor receptor mutations. Cancer. 2014;120:2090-8.
Li J, Wang W, Zhang Y, Cieślik M, Guo J, Tan M, Green MD, Wang W, Lin H, Li W, Wei S, Zhou J, Li G, Jing X, Vatan L, Zhao L, Bitler B, Zhang R, Cho KR, Dou Y, Kryczek I, Chan TA, Huntsman D, Chinnaiyan AM, Zou W. Epigenetic driver mutations in ARID1 A shape cancer immune phenotype and immunotherapy. J Clin Invest. 2020;130(5):2712-26.

Lin Y, Wang X, Jin H. EGFR-TKI resistance in NSCLC patients: mechanisms and strategies. Am J Cancer Res. 2014:4(5):411-35.

Mashtalir N, D'Avino AR, Michel BC, Luo J, Pan J, Otto JE, Zullow HJ, McKenzie ZM, Kubiak RL, St Pierre R, Valencia AM, Poynter SJ, Cassel SH, Ranish JA, Kadoch C. Modular organization and assembly of SWI/SNF family chromatin remodeling complexes. Cell. 2018;175:272-1288.

Michel BC, D'Avino AR, Cassel SH, Mashtalir N, McKenzie ZM, McBride MJ, Valencia AM, Zhou Q, Bocker M, Soares LMM, Pan J, Remillard DI, Lareau CA, Zullow HJ, Fortoul N, Gray NS, Bradner JE, Chan HM, Kadoch C. A noncanonical SWI:SNF complex is a synthetic lethal target in cancers driven by BAF complex perturbation. Nat Cell Biol. 2018;20:1410-20.

Naito T, Udagawa H, Umemura S, Sakai T, Zenke Y, Kirita K, Matsumoto S, Yoh K, Niho S, Tsuboi M, Ishii G, Goto K. Non-small cell lung cancer with loss of expression of the SWI/SNF complex is associated with aggressive clinicopathological features, PD-L1-positive status, and high tumor mutation burden. Lung Cancer. 2019;138:35-42.

Pagliaroli L, Trizzino M. The Evolutionary Conserved SWI/SNF Subunits ARID1A and ARID1B are key modulators of pluripotency and cell-fate determination. Front Cell Dev Biol. 2021;9:643361.

Peng XQ, Dai SK, Li CP, Liu PP, Wang ZM, Du HZ, Teng ZQ, Yang SG, Liu CM. Loss of Arid1 a promotes neuronal survival following optic nerve injury. Front Cell Neurosci. 2020;14:131.

Reisman D, Glaros S, Thompson EA. The SWI/SNF complex and cancer. Oncogene. 2009;28:1653-68.

Rolfo C, Giovannetti E, Hong DS, Bivona T, Raez LE, Bronte G, Buffoni L, Reguart N, Santos ES, Germonpre P, Taron M, Passiglia F, Van Meerbeeck JP, Russo A, Peeters M, Gil-Bazo I, Pauwels P, Rosell R. Novel therapeutic strategies for patients with NSCLC that do not respond to treatment with EGFR inhibitors. Cancer Treat Rev. 2014;40(8):990-1004.

Samartzis EP, Noske A, Dedes KJ, Fink D, Imesch P. ARID1A mutations and PI3K AKT pathway alterations in endometriosis and endometriosis-associated ovarian carcinomas. Int J Mol Sci. 2013;14(9):18824-49.

Santoni-Rugiu E, Melchior LC, Urbanska EM, Jakobsen JN, Stricker K, Grauslund $M$, Sørensen JB. Intrinsic resistance to EGFR-tyrosine kinase inhibitors in EGFR-mutant non-small cell lung cancer: differences and similarities with acquired resistance. Cancers (basel). 2019;11 (7):923.

Sharma SV, Lee DY, Li B, et al. A chromatin-mediated reversible drug-tolerant state in cancer cell subpopulations. Cell. 2010;141:69-80.

Somsuan K, Peerapen P, Boonmark W, Plumworasawat S, Samol R, Sakulsak N, Thongboonkerd V. ARID1A knockdown triggers epithelial-mesenchymal transition and carcinogenesis features of renal cells: role in renal cell carcinoma. FASEB J. 2019;33(11):12226-39.

Su YF, Tsai EM, Chen CC, Wu CC, ErTK. Targeted sequencing of a specific gene panel detects a high frequency of ARID1A and PIK3CA mutations in ovarian clear cell carcinoma. Clin Chim Acta. 2019;494:1-7.

Sun D, Zhu Y, Zhao H, Bian T, Li T, Liu K, Feng L, Li H, Hou H. Loss of ARID1A expression promotes lung adenocarcinoma metastasis and predicts a poor prognosis. Cell Oncol (Dordr). 2021 (Epub ahead of print).

Takahashi K, Takenaka M, Okamoto A, Bowtell DDL, Kohno T. Treatment strategies for ARID1A-deficient ovarian clear cell carcinoma. Cancers (Basel). 2021;13(8):1769.

Takeda T, Banno K, Okawa R, Yanokura M, lijima M, Irie-Kunitomi H, Nakamura K, lida M, Adachi M, Umene K, Nogami Y, Masuda K, Kobayashi Y, Tominaga E, Aoki D. ARID1 A gene mutation in ovarian and endometrial cancers (Review). Oncol Rep. 2016;35(2):607-13.

Tan CS, Gilligan D, Pacey S. Treatment approaches for EGFR-inhibitor-resistant patients with non-small-cell lung cancer. Lancet Oncol. 2015;16:e447-59.

Tomihara H, Carbone F, Perelli L, Huang JK, Soeung M, Rose JL, Robinson FS, Lissanu Deribe Y, Feng N, Takeda M, Inoue A, Poggetto ED, Deem AK, Maitra A, Msaouel P, Tannir NM, Draetta GF, Viale A, Heffernan TP, Bristow CA, Carugo A, Genovese G. Loss of ARID1A promotes epithelial-mesenchymal transition and sensitizes pancreatic tumors to proteotoxic stress. Cancer Res. 2021;81(2):332-43.

Turke AB, Zejnullahu K, Wu YL, et al. Preexistence and clonal selection of MET amplification in EGFR mutant NSCLC. Cancer Cell. 2010;17:77-88. 
Wang X, Nagl NG, Wilsker D, Van Scoy M, Pacchione S, Yaciuk P, Dallas PB, Moran E. Two related ARID family proteins are alternative subunits of human SWI/SNF complexes. Biochem J. 2004;15:319-25.

Wang W, Friedland SC, Guo B, O'Dell MR, Alexander WB, Whitney-Miller CL, Agostini-Vulaj D, Huber AR, Myers JR, Ashton JM, Dunne RF, Steiner LA Hezel AF. ARID1A, a SWI/SNF subunit, is critical to acinar cell homeostasis and regeneration and is a barrier to transformation and epithelial-mesenchymal transition in the pancreas. Gut. 2019;68(7):1245-58.

Wang Z, Chen K, Jia Y, Chuang JC, Sun X, Lin YH, Celen C, Li L, Huang F, Liu X, Castrillon DH, Wang T, Zhu H. Dual ARID1A/ARID1B loss leads to rapid carcinogenesis and disruptive redistribution of BAF complexes. Nat Cancer. 2020a;1 (9):909-22.

Wang T, Gao X, Zhou K, Jiang T, Gao S, Liu P, Zuo X, Shi X. Role of ARID1A in epithelial-mesenchymal transition in breast cancer and its effect on cell sensitivity to 5-FU. Int J Mol Med. 2020b;46(5):1683-94.

Wang L, Yang L, Wang C, Zhao W, Ju Z, Zhang W, Shen J, Peng Y, An C, Luu YT, Song S, Yap TA, Ajani JA, Mills GB, Shen X, Peng G. Inhibition of the ATM/ Chk2 axis promotes CGAS/STING signaling in ARID1A-deficient tumors. J Clin Invest. 2020c;130(11):5951-66.

Wiegand KC, Hennessy BT, Leung S, Wang Y, Ju Z, McGahren M, Kalloger SE, Finlayson S, Stemke-Hale K, Lu Y, Zhang F, Anglesio MS, Gilks B, Mills GB, Huntsman DG, Carey MS. A functional proteogenomic analysis of endometrioid and clear cell carcinomas using reverse phase protein array and mutation analysis: protein expression is histotype-specific and loss of ARID1A/BAF250a is associated with AKT phosphorylation. BMC Cancer. 2014;14:120.

Wilson MR, Reske JJ, Holladay J, Wilber GE, Rhodes M, Koeman J, Adams M, Johnson B, Su RW, Joshi NR, Patterson AL, Shen H, Leach RE, Teixeira JM, Fazleabas AT, Chandler RL. ARID1A and PI3-kinase pathway mutations in the endometrium drive epithelial transdifferentiation and collective invasion. Nat Commun. 2019;10(1):3554.

Wu S, Fukumoto T, Lin J, Nacarelli T, Wang Y, Ong D, Liu H, Fatkhutdinov N, Zundell JA, Karakashev S, Zhou W, Schwartz LE, Tang HY, Drapkin R, Liu Q, Huntsman DG, Kossenkov AV, Speicher DW, Schug ZT, Van Dang C,
Zhang R. Targeting glutamine dependence through GLS1 inhibition suppresses ARID1A-inactivated clear cell ovarian carcinoma. Nat Cancer. 2021;2(2):189-200

Yamagishi M, Uchimaru K. Targeting EZH2 in cancer therapy. Curr Opin Oncol. 2017;29(5):375-81.

Yang F, Xu Y, Liu C, Ma C, Zou S, Xu X, Jia J, Liu Z. NF-kB/miR-223-3p/ARID1A axis is involved in Helicobacter pylori CagA-induced gastric carcinogenesis and progression. Cell Death Dis. 2018;9(1):12.

Yang Y, Wang X, Yang J, Duan J, Wu Z, Yang F, Zhang X, Xiao S. Loss of ARID1A promotes proliferation, migration and invasion via the Akt signaling pathway in NPC. Cancer Manag Res. 2019;11:4931-46.

Yano S, Wang W, Li Q, et al. Hepatocyte growth factor induces gefitinib resistance of lung adenocarcinoma with epidermal growth factor receptoractivating mutations. Cancer Res. 2008;68:9479-87.

Yim SY, Kang SH, Shin JH, Jeong YS, Sohn BH, Um SH, Lee JS. Low ARID1A expression is associated with poor prognosis in hepatocellular carcinoma. Cells. 2020;9(9):2002.

Yoodee S, Peerapen P, Plumworasawat S, Thongboonkerd V. ARID1A knockdown in human endothelial cells directly induces angiogenesis by regulating angiopoietin-2 secretion and endothelial cell activity. Int J Biol Macromol. 2021;180:1-13.

Zhang Y, Xu X, Zhang M, Bai X, Li H, Kan L, Niu H, He P. ARID1A is downregulated in non-small cell lung cancer and regulates cell proliferation and apoptosis. Tumour Biol. 2014;35:5701-7.

Zhang L, Wang C, Yu S, Jia C, Yan J, Lu Z, Chen J. Loss of ARID1A expression correlates with tumor differentiation and tumor progression stage in pancreatic ductal adenocarcinoma. Technol Cancer Res Treat. 2018;17:1533034618754475.

\section{Publisher's Note}

Springer Nature remains neutral with regard to jurisdictional claims in published maps and institutional affiliations.
Ready to submit your research? Choose BMC and benefit from:

- fast, convenient online submission

- thorough peer review by experienced researchers in your field

- rapid publication on acceptance

- support for research data, including large and complex data types

- gold Open Access which fosters wider collaboration and increased citations

- maximum visibility for your research: over 100M website views per year

At BMC, research is always in progress.

Learn more biomedcentral.com/submissions 